\title{
Avaliação do desempenho motor em crianças com mucopolissacaridose II $^{1}$
}

\author{
Julie Souza de Medeiros Rochaa ${ }^{a}$, Alessandra Dounis Bonorandi ${ }^{b}$, Leilane Silva de Oliveirac, \\ Maria Natália Santos da Silva ${ }^{d}$, Viviane Ferreira da Silva ${ }^{\mathrm{e}}$
}

aTerapeuta Ocupacional, Especialista em Terapia Ocupacional no Desenvolvimento Infantil,

Universidade Federal de Minas Gerais - UFMG, Belo Horizonte, MG, Brasil

${ }^{\text {b}}$ Terapeuta Ocupacional, Especialista em Tecnologia Assistiva e Desenvolvimento Humano e Reabilitação na Área de Saúde da Criança, Professora Auxiliar, Departamento de Terapia Ocupacional, Universidade Estadual de Ciências da Saúde de Alagoas - UNCISAL, Maceió, AL, Brasil

'Acadêmica do $5^{\circ}$ ano do curso de Terapia Ocupacional, Universidade Estadual de Ciências da Saúde de Alagoas - UNCISAL, Maceió, AL, Brasil

${ }^{\mathrm{d}}$ Terapeuta Ocupacional, Mestranda em Psicologia Cognitiva, Universidade Federal de Pernambuco - UFPE, Recife, PE, Brasil

'Terapeuta Ocupacional, Associação Pestalozzi de Maceió, Maceió, AL, Brasil

\begin{abstract}
Resumo: A mucopolissacaridose (MPS) é uma doença multissistêmica decorrente da incapacidade do organismo em realizar um processo metabólico específico da degradação lisossômica dos glicosaminoglicanos (GAGs). $\mathrm{O}$ acúmulo progressivo de GAG em vários órgãos e tecidos resulta em desordens funcional e estrutural no indivíduo acometido pelas MPS. A MPS do tipo II trata-se de uma doença metabólica hereditária, ligada ao cromossomo X, cujo principal comprometimento é o atraso no desenvolvimento neuropsicomotor. O objetivo do estudo foi avaliar o desenvolvimento motor de crianças com MPS II. Foi realizado um estudo de caso com duas crianças, atendidas na APAE de Maceió (AL). Para a coleta de dados utilizou-se a Escala de Desenvolvimento Motor, e a análise de dados foi realizada por meio da comparação entre a idade cronológica de cada criança. Os resultados apontaram que as crianças apresentam perfil motor classificado em "Muito Inferior", corroborando com os achados na literatura e destacando a necessidade de intervenção precoce através da redução de danos e manutenção das habilidades remanescentes. O presente estudo também observou a característica progressiva dessa doença genética ainda pouco estudada. Dessa forma, destaca-se a importância de estudos sobre o desempenho motor, visando conhecer ao desenvolvimento de crianças com MPS II em diferentes etapas evolutivas, para fundamentar a prática clínica auxiliando na redução dos déficits funcionais, contribuindo, consequentemente, no desenvolvimento cognitivo, afetivo e social.
\end{abstract}

Palavras-chave: Mucopolissacaridose II, Desenvolvimento Infantil, Atividade Motora.

\section{Motor development evaluation in children with mucopolysacharidosis II}

\begin{abstract}
Mucopolysaccharidosis (MPS) is a multisystem disease caused by the body's inability to perform a metabolic process specific to lysosomal degradation of glycosaminoglycans (GAGs). The progressive accumulation of GAG in various organs and tissues results in functional and structural disorders in individuals affected by MPS. MPS type II is an inherited metabolic disease, linked to the X chromosome, whose main impairment is the delay in neuropsychomotor development. The purpose of this study was to evaluate the motor development of children affected by MPS II. A case study was carried out with two children, attending the "APAE Maceio"
\end{abstract}


institution. The Scale of Motor Development was used for data collection and data analysis was performed by comparing the chronological age of each child. Results showed that the children present motor profile classified as "Very Low", confirming the findings in the literature, highlighting the need for early intervention through harm reduction and maintenance of the remaining skills. This study also observed that the progressive characteristic of this genetic disease is still poorly studied. Therefore, the importance of studies on motor performance should be highlighted in order to determine the development of children affected by MPS II at different evolutionary stages to support the clinical practice in helping to reduce functional deficits, thus contributing to the cognitive, affective and social developments.

Keywords: Mucopolysacharidosis II, Child Development, Motor Activity.

\section{Introdução}

Segundo dados da Organização Mundial da Saúde (OMS), 7,6 milhōes de crianças nascem a cada ano com um defeito ou desordem genética grave, sendo 95\% delas nos países em desenvolvimento (MEIRA; ACOSTA, 2009). As mucopolissacaridoses (MPS) são doenças raras isoladamente, mas em conjunto têm incidência estimada de 1:10000 a 1:25000 (PINTO, 2005).

As MPS são um grupo de doenças genéticas hereditárias causadas pela deficiência de uma das enzimas lisossômicas responsáveis por uma etapa específica na degradação dos glicosaminoglicanos (GAGs), acarretando o acúmulo progressivo nos tecidos e representam cerca de $32 \%$ de erros metabólicos, causando dez síndromes principais e vários subtipos. Os GAGs são carboidratos de cadeia longa, que se ligam a uma proteína central do tecido conjuntivo e absorvem grande quantidade de água, adquirindo consistência mucoide, viscosa, o que garante a essa estrutura uma funçáo lubrificante e de união entre os tecidos. Assim, quando a atividade das enzimas estão diminuídas ou ausentes, os GAGs se acumulam nos tecidos e o seu excesso é eliminado pela urina. O acúmulo progressivo nos tecidos (ósseos, cardíacos e nervosos) causa suas desordens funcional e estrutural (ANDERSON; SHAPIRA, 2000; GRABOWSKI, 2002; MARTINS, 2002).

Apesar das MPS apresentarem, em comum, características crônicas e progressivas, as manifestaçôes clínicas variam de acordo com a enzima que está em falta no portador da doença, o que irá distinguir, consequentemente, o tipo de MPS.

No caso da MPS do tipo II, as manifestações principais encontradas são: face grosseira, alterações esqueléticas, baixa estatura, contratura articular, retardo mental, infecçóes recorrentes, surdez e cardiopatia. Podem-se distinguir duas variantes de acordo com a clínica: a) forma grave - MPS II A - com início ao redor de dois anos caracterizada por face grosseira, baixa estatura, disostose múltipla, surdez, hepatoesplenomegalia, deterioração mental progressiva e morte ao redor da segunda década de vida e b) forma atenuada - MPS II B - caracterizada por iniciar mais tardiamente, com leve ou nenhum retardo mental e com alguns pacientes sobrevivendo até a quinta ou sexta década. Algumas crianças podem ter dismorfias adicionais, crises convulsivas, e cada órgão e sistema afetado poderá apresentar manifestaçóes decorrentes do acúmulo de GAGs de diferentes maneiras (PINTO, 2005). Lesóes papulares no dorso, braços e nádegas também são típicas da MPS II, ocorrendo muito raramente em outras MPS (KNOELL; TUNNESSEN JUNIOR, 2000; PINTO et al., 2006; SANJURJO-CRESPO, 2007).

A forma clássica da MPS II se inicia fenotipicamente a partir do primeiro ano de vida, mas algumas formas se expressam na época adulta (SANJURJO-CRESPO, 2007; TURTELLI, 2002).

Todas as síndromes são do tipo autossômico recessivo, com exceção da MPS II, também chamada de síndrome de Hunter, que é ligada ao cromossomo X (DIAMENT; CYPEL, 1996; LEISTNER; GIUGLIANI, 1998; LYNN et al., 2000; MARTINS, 2002; PINTO et al., 2006; SANJURJO-CRESPO, 2007; TURTELLI, 2002). Dessa forma, o gene com defeito é carregado em um dos cromossomos $\mathrm{X}$ da mãe, que como tem dois cromossomos $\mathrm{X}$, o com defeito é anulado pelo outro normal. A mãe portadora do gene da doença tem uma chance de $50 \%$ de ter um filho com a doença e $50 \%$ de ter uma filha que também pode passar o gene aos seus filhos e filhas (MARTINS, 2002).

No que se refere ao diagnóstico, na MPS é caracterizado através da avaliação clínica, baseada na investigaçáo de possíveis comprometimentos orgânicos e da avaliação laboratorial (VIANA et al., 2010). Diante de uma suspeita de MPS podem-se realizar primariamente exames na urina, que servem para o direcionamento da investigaçáo da doença 
(SCHWARTZ et al., 2001). Os exames iniciais que são realizados na urina podem ser classificados em quantitativo e qualitativo (PINTO, 2005). Os testes quantitativos servem para medir a quantidade de GAGs excretados e os testes qualitativos (como a cromatografia e a eletroforese) para identificar quais os GAGs aumentados (PINTO, 2005). No caso da MPSII, encontramos dermatan sulfato e heparan sulfato em excesso. O diagnóstico definitivo, no entanto, é realizado através da dosagem da atividade enzimática da IDS (iduronato-2-sulfatase) em plasma, leucócitos ou fibroblastos (PINTO, 2005).

Também é possível realizar diagnóstico pré-natal da deficiência de IDS através da medida da atividade enzimática em células cultivadas do líquido amniótico e nas vilosidades coriônicas. Como a atividade da IDS nas mulheres portadoras é usualmente normal (NEUFELD; MUENZER, 2001; MORINI, 2007; PINTO, 2005), sua identificação se baseia na pesquisa da mutação previamente identificada no caso índice dessa família (RARTHMANN et al., 1996).

O diagnóstico diferencial deve ser feito com as demais mucopolissacaridose e com algumas das outras doenças lisossômicas, o que clinicamente nem sempre é possível, exigindo exames complementares e dosagens enzimáticas específicas (PINTO, 2005).

O diagnóstico definitivo é confirmado pela análise de enzimas lisossomais no sangue, em leucócitos ou fibroblastos da pele. No momento em que é feito o diagnóstico de uma criança com MPS, é recomendado realizar o aconselhamento genético com a finalidade de informar à família sobre os riscos de recorrência, o prognóstico e a gravidade da doença (CAMELIER, 2011).

Diante de tais reflexôes, torna-se relevante destacar o caráter genético e progressivo da MPS II, em que existe um grande risco de recorrência numa mesma família, inclusive na mesma prole. Devido a esse fator, são imprescindíveis a orientação e o acompanhamento genético em famílias que já têm um membro diagnosticado. O diagnóstico precoce e a terapêutica correta são indispensáveis para uma melhor qualidade de vida desses pacientes. Além disso, torna-se importante também o incentivo através de programas de prevenção quanto a esta patologia, numa tentativa de minimizar sua incidência através da orientação à população. Nesse contexto, destaca-se a escassez de trabalhos que apresentem tais propostas.

Os tratamentos correntes para a MPS II são sintomáticos e de suporte. A princípio, acreditava-se que esse distúrbio deveria ser tratado com enzimas exógenas, desse modo foram testados tratamentos com transplantes de medula óssea e transplante de âmnio, mas não foram alcançados resultados satisfatórios e esses tipos de tratamento não puderam alterar o curso clínico da doença (NEUFELD; MUENZER, 2001). Atualmente existe tratamento para correção do metabolismo para algumas doenças lisossômicas como a MPS I, a doença de Gaucher e a doença de Fabry, utilizando a terapia por reposição enzimática (TRE), que envolve a infusão de pacientes com enzima sintética. Brevemente tal tratamento também estará disponível para a MPS II no Brasil (MORINI, 2007).

Dentre as características clínicas descritas na literatura a respeito das MPS II, o atraso no desenvolvimento motor será o mais abordado neste trabalho, devido ao impacto que provoca na independência e na qualidade de vida da criança.

O desenvolvimento infantil abrange modificaçôes no plano motor, intelectual, emocional e social, sendo o desenvolvimento motor uma contínua alteraçấo no comportamento ao longo da vida que acontece por meio das necessidades de tarefa, da biologia do indivíduo e o ambiente em que vive, sendo viabilizado tanto pelo processo evolutivo biológico quanto pelo social. A sequência de desenvolvimento motor é a mesma para todas as crianças e apenas a velocidade varia, havendo uma interdependência entre as mudanças. Esse desenvolvimento caracteriza-se pela aquisição de um amplo espectro de habilidades motoras, que possibilita à criança um amplo domínio do seu corpo em diferentes posturas (estáticas e dinâmicas), locomover-se pelo meio ambiente de variadas formas e manipular objetos e instrumentos diversos. Essas habilidades básicas são requeridas para a condução de rotinas diárias em casa e na escola, como também servem a propósitos lúdicos, tão característicos na infância (ANDRADE; LUFT; ROLIM, 2004; SANTOS; DANTAS; OLIVEIRA, 2004; TORRALVA et al., 1999).

Para Santos, Dantas e Oliveira (2004, p. 33):

A relação de interdependência entre as fases de habilidades básicas e de habilidades especializadas denota a importância das aquisiçóes motoras iniciais da criança, que atende não só as necessidades imediatas na $1^{\text {a }}$ e $2^{a}$ infância, como traz profundas implicações para o sucesso com que habilidades específicas são adquiridas posteriormente.

Brown e Gordon (1987 apud GUERZONI et al., 2008, p. 18) observaram que crianças com disfunçóes neuromotoras apresentam menos variedade e tempo dedicado às atividades cotidianas, menor participação 
social nas tarefas de casa e em atividades recreativas, comparadas com crianças típicas.

Em crianças com MPS II o desempenho das atividades de vida diária (AVDs) é, muitas vezes, a queixa principal de pais e familiares, e/ou da própria criança, visto que o envolvimento do sistema músculo-esquelético e do sistema nervoso central compromete grandemente o desempenho funcional dos indivíduos (MORINI, 2007). As principais causas para o comprometimento funcional nas AVDs são: comprometimento do tecido conjuntivo levando à perda da mobilidade articular, defasagem nas amplitudes de movimentos de várias articulaçôes (especialmente em ombros e cotovelos), perda de força muscular em diversos grupos musculares (principalmente flexores e extensores dos dedos das mãos e pronadores e supinadores do antebraço), alterações posturais características e disostose múltipla, alterações nos nervos periféricos e no túnel do carpo levando à perda funcional do polegar e deficiência significativa em combinação com a displasia óssea, mão em garra. Tais alteraçóes contribuíram para os déficits encontrados nas atividades de vida diária, principalmente pentear os cabelos, vestir uma camiseta e amarrar os sapatos (MORINI, 2007). Contudo, o desempenho de tais atividades é importante para que a criança seja capaz de satisfazer suas necessidades básicas, garantindo-lhe maior independência e participação em seu ambiente domiciliar.

Para Santos, Dantas e Oliveira (2004, p. 34):

Dentre as razôes que têm levado ao interesse crescente pelos conhecimentos acerca do desenvolvimento motor, destacam-se o papel dos padróes motores no curso de desenvolvimento humano, com implicaçóes para a educação da criança, bem como para reabilitação de indivíduos com atrasos ou desvios de desenvolvimento, e a adequaçáo e estruturaçấo de ambientes e tarefas motoras aos estágios de desenvolvimento, de forma a facilitar e estimular esse processo.

Tendo em vista os comprometimentos decorrentes da MPS torna-se relevante avaliar o desempenho motor de crianças acometidas por essa patologia, traçando seus perfis para identificar seus déficits, numa tentativa de prevenir e/ou minimizar o atraso neuropsicomotor por meio de um programa de intervenção específico, proporcionando melhor qualidade de vida a essa população.

Nesse sentido, destacamos a escala de desenvolvimento motor proposta por Rosa Neto (2002), que compreende um conjunto de provas diversificadas e de dificuldade graduada, levando a uma exploração minuciosa de diferentes setores do desenvolvimento, permitindo avaliar o nível de desenvolvimento motor da criança de acordo com a idade cronológica, considerando êxitos e fracassos. Os resultados de uma prova motora permitem determinar o avanço ou atraso motor de uma criança naquele aspecto avaliado. Essa escala compreende testes motores nos seguintes componentes: motricidade fina, motricidade global, equilíbrio, esquema corporal, organização espacial e temporal.

O objetivo deste estudo foi avaliar o desenvolvimento motor de duas crianças com mucopolissacaridose do tipo II, traçando um perfil a fim de identificar os déficits específicos nessa área para orientar a prática clínica em terapia ocupacional.

\section{Procedimentos metodológicos}

Trata-se de um estudo descritivo, de abordagem qualitativa, do tipo relato de caso, onde a amostra foi composta por duas crianças com diagnóstico fechado de mucopolissacaridose do tipo II por um geneticista e comprovado em prontuário, na idade cronológica de 9 e 11 anos, do gênero masculino. $\mathrm{O}$ Termo de Consentimento Livre e Esclarecido (TCLE) foi assinado pela mãe e só então teve início a etapa de coleta de dados. As avaliaçôes foram realizadas na sala de Terapia Ocupacional da Associação dos Pais e Amigos dos Excepcionais (APAE) em Maceió (AL), onde as duas crianças recebem acompanhamento. A pesquisa foi desenvolvida após aprovação do Comitê de Ética em Pesquisa da instituição onde foi realizado o estudo, conforme a Resoluçáo no 196/96 do Conselho Nacional de Saúde, referente à pesquisa com seres humanos.

O instrumento utilizado foi a escala de desenvolvimento motor (EDM), desenvolvida e validada por Rosa Neto (2002). A referida escala é de administração individual, em ambiente tranquilo, com duraçáo entre 30 e 45 minutos, sendo indicada para crianças com dificuldades na aprendizagem escolar, atrasos no desenvolvimento neuropsicomotor, problemas na fala, cálculo e escrita, problemas de conduta, alteraçôes neurológicas, sensoriais etc. Envolve um conjunto de provas diversificadas e específicas para cada faixa etária (2 a 11 anos) em cada elemento da motricidade (motricidade fina, motricidade global, equilíbrio, esquema corporal, organização espacial, organização temporal e lateralidade). A complexidade da prova a ser realizada aumenta de acordo com a idade e só termina quando a criança não consegue bom desempenho, identificando assim sua idade motora 
(IM) naquele componente, que será positiva se for superior à idade cronológica e negativa se for inferior. A pontuação da escala oferece uma idade motora geral (IMG), obtida através da soma dos resultados positivos obtidos nas provas motoras $\left[\frac{\mathrm{IM} 1+\mathrm{IM} 2[\ldots]+\mathrm{IM} 6}{6}\right]$, dividida por seis sendo os valores expressos em meses. Para classificar o desenvolvimento motor, calcula-se o quociente motor geral (QMG) por meio da divisão entre a IMG e a idade cronológica (IC) $\left[\frac{I M G}{I C}\right]$, multiplicada por 100. O valor obtido neste cálculo deve ser comparado aos números tabelados da escala, que classificará a criança nos níveis: muito inferior (69 pontos ou menos), inferior (70-79), normal baixo (80-89), normal médio (90-109), normal alto (110-119), superior (120-129) e muito superior (130 ou mais). Os resultados podem ser inseridos em uma base de dados da própria escala (adquirida junto com o material e o manual), onde os cálculos citados são realizados automaticamente, gerando gráficos e tabelas individuais que podem ser armazenados.

Tendo em vista os comprometimentos dos participantes, as avaliaçóes iniciaram de acordo com a sequência do Manual de Avaliação Motora e não segundo as idades cronológicas.

Após observação minuciosa em cada prova, os resultados foram analisados conforme todos os pontos válidos por prova motora, conforme os procedimentos da EDM e os dados foram armazenados na base de dados da EDM.

\section{Resultados e discussão}

\subsection{Descrição dos casos}

A população estudada constituiu-se de duas crianças com diagnóstico de mucopolissacaridose do tipo II, ambas do gênero masculino, com idade de 9 e 11 anos, identificadas respectivamente como M1 e M2. Os dados sobre as características gerais das crianças estáo apresentados na Tabela 1.

\subsubsection{Caso 1}

M1, 9 anos, sexo masculino, negro, matriculado no $4^{\circ}$ ano do ensino fundamental, natural de Teotônio Vilela (AL) e o $5^{\circ}$ filho de uma prole de 6 , onde 3 são do gênero feminino e 3 do gênero masculino, os quais são acometidos pela patologia. Segundo informaçóes fornecidas pela genitora, a criança nascera de parto normal, aos 9 meses, com peso adequado para a idade gestacional. Teve seu desenvolvimento neuropsicomotor normal até 2 anos, sentando com 6 meses, andando com 10 e falando com aproximadamente 1 ano; quando desacelerou o crescimento e começou a ter dificuldade em fazer movimentos de flexão dos dedos das mãos associada ao déficit na coordenação motora, mas não procurou auxílio médico por supor que a criança era anã e por ter características semelhantes aos irmáos portadores da patologia. Teve o diagnóstico genético da patologia com 4 anos de idade, onde continua sendo acompanhado pelo médico geneticista. Atualmente recebe acompanhamento da assistência social, fisioterapia motora e respiratória, fonoaudiologia, psicologia, terapia ocupacional e especialidades médicas (cardiologia, endocrinologia, genética etc.).

Possui face grosseira, baixa estatura (1,24 m), obstrução nasal, hepatomegalia, cardiopatia, hérnia umbilical, rigidez articular, leve dificuldade de aprendizado, dificuldade na compreensão de comandos simples e memória, dificuldade na audição, porém na interação com as pessoas e o ambiente a criança não apresenta dificuldades.

Em relação às atividades de vida diária (AVDs), a criança se alimenta sozinha fazendo uso de garfo e faca, não realiza higiene oral, não toma banho sozinha, penteia parcialmente os cabelos, veste-se e despe-se sozinha manuseando velcro e botáo pequeno e grande, mas náo escolhe as peças, calça sapato com velcro e náo manuseia cadarço. Esses resultados serão discutidos mais adiante. Realiza atividades de escrita, e não possui nenhum tipo de tecnologia assistiva para as AVDs.

Nos aspectos relativos às atividades instrumentais de vida diária (AIVDs), M1 não utiliza medicamento sozinho, não prepara a comida, mas vai à escola

Tabela 1. Características gerais da população estudada. Maceió (AL), 2009.

\begin{tabular}{ccc}
\hline Características gerais & M1 & M2 \\
\hline Idade & 09 anos & 11 anos \\
Sexo & M & M \\
Raça & Negra & Negra \\
Escolaridade & Analfabeto & $4^{\circ}$ ano do ens. fundamental \\
Naturalidade & Teotônio Vilela - AL & Teotônio Vilela - AL \\
\hline
\end{tabular}


sozinho, onde cursa o $4^{\circ}$ ano do ensino fundamental, e como lazer gosta de assistir televisão.

\subsubsection{Caso 2}

M2, 11 anos, sexo masculino, negro, analfabeto, natural de Teotônio Vilela (AL) e o $4^{\circ}$ filho de uma prole de 6 , onde 3 sáo do sexo feminino e 3 do sexo masculino acometidos pela patologia. Segundo relatos da genitora, a criança nasceu aos 9 meses de parto normal, com peso adequado para a idade gestacional, sentou aos 6 meses, andou com 10 e falou com aproximadamente 1 ano. Aos 2 anos de idade começou a apresentar rigidez articular nas interfalangeanas distais, cansaço e barriga distendida. Foi encaminhado ao geneticista aos 7 anos de idade, devido à semelhança da sintomatologia dos irmãos. Recebe acompanhamento da assistência social, fisioterapia motora e respiratória, fonoaudiologia, psicologia, terapia ocupacional e especialidades médicas (cardiologia, endocrinologia, genética etc.).

Apresenta alteraçôes na face (grosseira), baixa estatura (1,14 m), obstrução nasal, hepatomegalia, cardiopatia, hérnias umbilicais, rigidez articular, dificuldade de aprendizado, dificuldade na compreensão de comandos simples e memória, dificuldade na audição, agressividade e dificuldade na interação com as pessoas e o ambiente.

Nas AVDs, a criança se alimenta independente fazendo uso de garfo e faca, é dependente total nas atividades de autocuidado (higiene oral, íntima, banho e pentear-se), mas apresenta controle de esfíncteres. É dependente total no vestuário, não manuseia zíper, botão e cadarço, também não escolhe as peças. Não escreve com lápis ou caneta, e não possui nenhum tipo de tecnologia assistiva para as AVDs.

Com relação às AIVDs, a criança não utiliza medicamentos sozinha, não prepara a comida, não estuda e como lazer gosta de brincar com galinhas e patos, construir gaiolas e cativeiros para esses animais.

\subsection{Análise dos resultados}

Os resultados foram analisados por meio da idade motora obtida em cada elemento da motricidade avaliados individualmente. Esses dados são apresentados na Tabela 2.

Desenvolvimento motor: De acordo com os resultados da Tabela 2, verificou-se discrepância de 53 meses em M1 e de 91 meses em M2 entre a média de idade cronológica e a média de idade motora geral. $\mathrm{O}$ quociente motor geral obtido classificou a amostra em nível "Inferior" e "Muito Inferior", respectivamente. M2 manteve o padrão motor classificado em "Muito Inferior" em todas as variáveis avaliadas. Já M1 classificou-se num perfil "Inferior" nos componentes de equilíbrio, esquema corporal, organização espacial e organização temporal.

Este estudo corrobora com a literatura, uma vez que os dados encontrados comprovam o atraso no desenvolvimento motor nas crianças avaliadas. Além disso, contribui com a identificação e descrição dos principais déficits encontrados nos dois casos. $\mathrm{Na}$ literatura pesquisada, náo foram encontrados estudos relativos à avaliaçáo motora de pacientes com MPS II, a maioria deles enfoca outros aspectos relacionados ao desenvolvimento da patologia e geralmente citam outras MPS.

De acordo com Pinto et al. (2006), existem várias manifestações clínicas encontradas nesta patologia, dentre elas contraturas articulares e atraso do desenvolvimento neuropsicomotor.

As manifestaçôes osteoarticulares são progressivas e limitam os movimentos. As alterações ósseas se caracterizam por dificuldade na mobilidade articular, mão em garra e disostose múltipla (PINTO, 2005). Os pacientes com mucopolissacaridose tipo

Tabela 2. Resultados obtidos na Escala Motora - em meses. Maceió (AL), 2009.

\begin{tabular}{lcc}
\hline \multicolumn{1}{c}{ Variáveis } & M1 & M2 \\
\hline Idade cronológica & 117 & 131 \\
Idade motora geral & 64 & 40 \\
Quociente motor geral & 54,7 & 30,5 \\
Motricidade fina & 96 & 60 \\
Motricidade global & 84 & 48 \\
Equilíbrio & 72 & 48 \\
Esquema corporal & 72 & 48 \\
Organização espacial & 72 & 36 \\
Organização temporal & 72 & 36 \\
Lateralidade & Destro completo & Cruzada \\
\hline
\end{tabular}


II também podem apresentar lesóes papulares e nodulares que se distribuem simetricamente nas escápulas, linhas axilares posteriores, no tórax, pescoço e nos membros superiores (PINTO, 2005). Tais afirmativas contribuem para uma reflexão acerca dos achados encontrados nesta pesquisa, especialmente no caso 1 , podendo indicar a presença de déficit no desenvolvimento da coordenação fina e destreza manual nessa criança.

A coordenação motora fina é a função motora necessária para a realizaçáo de atividades que exijam destreza (OKUDA, 2011). Motricidade fina é uma atividade de movimento espacialmente pequena, que requer um emprego de força mínima, mas grande precisão ou velocidade ou ambos, sendo executada principalmente pelas mãos e dedos (MEINEL, 1984, p. 154). Habilidades motoras finas requerem a capacidade de controlar os músculos pequenos do corpo, a fim de atingir a execução bem-sucedida da habilidade (MAGILL, 1984).

Em conjunto, essas alteraçôes constituem um grande empecilho nas tarefas cotidianas do paciente com MPS tipo II, e o acompanhamento com terapeuta ocupacional pode trazer benefícios a partir de uma avaliação mais específica e minuciosa a fim de identificar detalhadamente as principais dificuldades a serem trabalhadas e elaborar estratégias para traçar um plano de tratamento voltado às necessidades de cada paciente.

Tendo em vista que a terapia ocupacional é uma profissão da saúde que auxilia o indivíduo a recuperar, desenvolver e construir habilidades que são importantes para sua independência funcional, saúde, segurança e integração social (NOORDHOEK; LOSCHIAVO, 2005), em pacientes com MPS tipo II, a intervençấo terapêutica pode abordar as atividades de vida diária (AVD) que fazem parte do cotidiano e incluem tarefas de automanutenção como banho, vestuário, alimentação, uso do banheiro, higiene oral e comunicação; atividades instrumentais de vida diária (AIVDs) que estão relacionadas com atividades de cuidado com a casa, administraçáo do ambiente (limpar a casa, cuidar da roupa, da comida, usar equipamentos domésticos, fazer compras, usar transporte público, controlar a própria medicação etc.); pode auxiliar ensinando estratégias para compensar seus problemas motores, adaptaçáo de materiais, avaliação do ambiente e indicação de modificaçóes de acordo com suas necessidades, assim como oferecer oportunidades adequadas para praticar e aprender habilidades motoras, e se conscientizar tanto de seus pontos fortes como de suas limitaçóes, para que possa lidar com suas dificuldades (MAZER; BARBA, 2010).
Sendo assim, os objetivos do tratamento envolvem: promover a manutenção ou aumento da capacidade funcional; realizar um programa de exercícios regulares para manutenção da força muscular e amplitude de movimento, evitando-se assim a rigidez articular; trabalhar coordenação motora; orientar o paciente quanto a técnicas de proteção articular e conservação de energia; favorecer sua inserção social e monitorar a adesáo do paciente ao tratamento, oferecendo-lhe suporte emocional e os esclarecimentos que ele necessitar, visando proporcionar maior grau de autonomia e independência, visto que trata-se de uma patologia progressiva e que acomete diversas áreas de desempenho (SPENCER, 2002; BUCKNER, 2004).

O caráter progressivo da MPS II é confirmado também neste estudo, tendo em vista que a idade motora da criança com maior idade foi menor em relação à criança mais nova. Isso deve ser considerado na avaliação da eficácia de protocolos de tratamento para essa condição.

Em estudo realizado por Sanjurjo-Crespo (2007), 93\% dos portadores de mucopolissacaridose II apresentam mão em garra e $95 \%$ possuem rigidez articular. A partir desse dado, e entendendo a motricidade fina como atividade manual com emprego de força mínima, a fim de atingir uma resposta precisa à tarefa (ROSA NETO, 2002), o presente estudo observou que tais características estavam presentes nos participantes da pesquisa e, portanto, apresentaram dificuldade em desempenhar as tarefas com eficácia. Entretanto, M1 obteve um bom desempenho dentro de suas limitaçóes, ao contrário de M2, que obteve resultados insatisfatórios por apresentar sintomatologia mais acentuada.

A motricidade global refere-se aos movimentos dinâmicos corporais, envolvendo um conjunto de movimentos coordenados de grandes grupos musculares (ROSA NETO, 2002). Nesse aspecto também houve dificuldade devido à presença de displasia pélvica e deformidades nas vértebras presentes nas crianças e mais uma vez M1 apresentou melhor desempenho em relação a M2.

Equilíbrio é a capacidade do organismo de manter posturas, posiçóes e atitudes, compensando e anulando todas as forças que agem sobre o corpo (ROSA NETO, 2002); dessa forma, é necessário que as estruturas esqueléticas e articulares estejam preservadas. Diante do exposto foi observado grande dificuldade em ambas as crianças, não havendo discrepâncias nesse componente.

Esquema corporal refere-se à capacidade de discriminar com exatidão as partes corporais $\mathrm{e}$ a habilidade de organizar as partes do corpo na execução de uma tarefa (ROSA NETO, 2002). 
É possível notar que as duas crianças apresentaram perfil "Muito Inferior", entretanto, M2 obteve resultado muito mais baixo (idade motora de 4 anos), evidenciando a grande disparidade entre as duas crianças e comprovando o caráter progressivo da MPS II.

Organização espacial envolve tanto a noção do espaço do corpo como o espaço que o rodeia, referindo-se à habilidade de avaliar com precisão a relação entre o indivíduo e o ambiente (ROSA NETO, 2002). Nesse aspecto M1 alcançou idade motora duas vezes maior que M2, confirmando mais uma vez a progressividade dessa doença.

Organização temporal refere-se à percepção do tempo envolvendo o conhecimento da ordem e duração dos acontecimentos (ROSA NETO, 2002). Dentro dessa perspectiva e analisando os dados, houve baixo desempenho em ambas as crianças. Isso se deve, provavelmente, à pouca experiência vivenciada nessa área pelas mesmas.

Conhecemos a lateralidade como a capacidade de controlar os dois lados do corpo juntos ou separadamente (ROSA NETO, 2002). Diante dos resultados, M1 tem a lateralidade definida como destro completo e M2 como cruzada.

A lateralidade não definida pode resultar em problemas de aprendizagem (FONSECA, 1995). As noçóes de corpo, espaço e tempo têm que estar intimamente ligadas para que possamos entender o movimento. O corpo se coordena e movimenta dentro de um espaço determinado, em função do tempo, e em relação a um sistema de referências (MANSUR et al., 2006).

Sabe-se que a motricidade global exige a interação entre tônus e o equilíbrio, além da coordenação da lateralidade, da noção do corpo e da estruturaçáo espaço-temporal, harmonizando assim o espaço intracorporal com o extracorporal (FONSECA, 1995). Podemos entender, portanto, que a criança que apresenta um atraso nesse componente pode ter comprometimento no desempenho de algumas AVD, como banhar-se ou vestir-se, por exemplo, uma vez que são atividades que exigem trabalho intensivo e em conjunto de todos esses elementos que compóem a motricidade global.

A orientação espacial é a capacidade que tem o indivíduo de situar-se e orientar-se, localizar outra pessoa ou objeto dentro de um determinado espaço. Quando a criança aprende noções de situação, tamanho, movimentos, formas, volume etc., ela atingirá a etapa de orientação espacial, ou seja, ela passa a ter acesso a um espaço orientado a partir de seu próprio corpo, multiplicando suas possibilidades de açôes eficazes (MANSUR, et al., 2006). E a estruturação temporal proporciona à criança a consciência do desenvolvimento das açóes no tempo. A estruturação espaço-temporal é um dado importante para uma adaptação favorável do individuo, pois ela permitirá não só movimentar-se e reconhecer-se no espaço, mas também concatenar e dar sequências aos seus gestos, localizar as partes do seu corpo e situá-las no espaço, associar sua atividade e organizar sua vida cotidiana (MANSUR, et al., 2006).

Em razão das manifestaçôes clínicas da MPS II e os resultados obtidos neste trabalho é importante destacar a relevância do acompanhamento multidisciplinar para prevenir e diagnosticar precocemente os agravos, que podem ser tratados, melhorando a qualidade de vida do portador de mucopolissacaridose, oferecendo apoio e orientação à família. Uma vez que náo existe um tratamento curativo para as MPS, o aconselhamento genético familiar é de suma importância dentro desse processo com a finalidade de informar à família sobre os riscos de recorrência, o prognóstico e a gravidade da doença (CAMELIER, 2011), além do diagnóstico pré-natal. $\mathrm{O}$ aconselhamento genético oferece uma oportunidade única para o planejamento familiar dessas famílias em que já há casos de MPS. Os serviços de aconselhamento genético devem também orientar os pais quanto às características do desenvolvimento do filho e quais os atendimentos/tratamentos que se fazem necessários para o melhor desenvolvimento da criança. Através do aconselhamento genético deve-se alcançar o diagnóstico acurado, a identificação de indivíduos em risco clínico e reprodutivo; deve-se assegurar que paciente e família entendam como a herança contribui para a doença e para os riscos de recorrência. É preciso alcançar também a linha de ação que atenda às necessidades e o ajustamento psicológico e social dos pacientes e famílias. Além de tudo isso, em muitas situaçóes, o paciente e a família devem entender que o diagnóstico de uma condição genética implica riscos, benefícios, limitaçóes e consequências psicológicas e econômicas (PERGAMENT, 1997). Neste caso, especificamente, cabe ressaltar que as crianças recebem acompanhamento genético na mesma instituição em que elas são atendidas pela equipe multiprofissional. Entretanto, a mãe só procurou ajuda após o nascimento do sexto filho, quando então recebeu orientaçóes quantos à etiologia da doença e riscos de recorrência.

Dentro da equipe multiprofissional a presença do terapeuta ocupacional é fundamental, onde, dentre os objetivos de atuação, podemos destacar: manter mobilidade articular acometida, favorecer 
o desenvolvimento neuropsicomotor, promover adaptaçôes dos utensílios das atividades de vida diária (AVDs), mobiliários e ambiente domiciliar, visando otimizar a funcionalidade, a autonomia e a qualidade de vida das crianças portadoras da doença, e evitar a progressão de algumas complicaçóes da patologia.

\section{Conclusão}

A mucopolissacaridose II é uma doença progressiva que causa deterioração multissistêmica e atraso importante no desenvolvimento motor. Os resultados desse estudo indicam que as crianças avaliadas apresentaram grandes déficits motores, classificando-se em níveis "Inferior" e "Muito Inferior", de acordo com a Escala de Desenvolvimento Motor, confirmando os achados na literatura que referem atraso no desenvolvimento psicomotor em portadores de mucopolissacaridose do tipo II e evidenciando a característica progressiva dessa doença genética ainda pouco estudada.

Contudo, observa-se que a importância do tratamento terapêutico ocupacional junto a pacientes com MPS tipo II ainda é escassa em pesquisas científicas, fato comprovado pelo levantamento bibliográfico realizado nas bases de dados: Scielo, BVS, periódicos da Capes e Google Acadêmico, onde foram pesquisadas publicaçôes dos últimos dez anos até o momento, e não foram encontrados muitos trabalhos que referencie a mucopolissacaridose tipo II relacionando a atuação do terapeuta ocupacional junto a essa clientela. Assim, essa é a primeira contribuição deste trabalho, que destaca a importância de mais pesquisas que incluam a abordagem desse profissional, visando auxiliar os profissionais da área a identificar limitaçôes nos aspectos funcionais e melhor direcionamento no serviço prestado, além de divulgar a atuação e prática do terapeuta ocupacional. Nota-se também que o presente estudo contribui para uma reflexão sobre os déficits na coordenação motora fina, refletindo no comprometimento do desempenho nas AVD e AIVD, ampliando os conhecimentos já existentes acerca dessa patologia . Dessa forma, destaca-se a importância de estudos sobre o desempenho motor, que abordem mais especificamente a coordenação motora fina, visando conhecer o desenvolvimento de crianças com MPS II em diferentes etapas evolutivas, bem como sobre as intervenções do terapeuta ocupacional junto a esses pacientes, para fundamentar a prática clínica auxiliando na redução dos déficits funcionais, contribuindo, consequentemente, no desenvolvimento cognitivo, afetivo e social.
Faz-se ainda importante trabalhos informativos visando prevenir a recorrência de casos, principalmente na MPS II, que tem herança ligada ao cromossomo X.

\section{Referências}

ANDERSON, H. C.; SHAPIRA, E. As Mucopolissacaridoses. In: GOLDMAN, L.; BENNETT J. C. Cecil Tratado de Medicina Interna. 21. ed. Rio de Janeiro: Guanabara Koogan, 2001. p. 1241-1243.

ANDRADE, A.; LUFT, C. D. B.; ROLIM, M. K. S. B. O desenvolvimento motor, a Maturação das áreas corticais e a atenção na aprendizagem motora. Revista Digital, Buenos Aires, v. 10, n. 78, nov. 2004.

BUCKNER, W. S. Artrite. In: PEDRETTI, L. W.; EARLY, M. B. Terapia Ocupacional: capacidades práticas para disfunçôes físicas. São Paulo: Roca, 2004. p. 847-874.

CAMELIER, M. V. Diagnóstico de Mucopolissacaridose tipo IVA em amostras de sangue impregnado em papel filtro. 2011. 96 f. Tese (Mestrado em Ciências Médicas)Universidade Federal do Rio Grande do Sul, Rio Grande do Sul, 2001. Disponível em: <http://www.bibliotecadigital. ufrgs.br/da.php?nrb=000780732\&loc $=2011 \& \mathrm{l}=42 \mathrm{fda} 5 \mathrm{~d}$ a64280e98>. Acesso em: 17 set. 2011.

DIAMENT, A.; CYPEL, S. Neurologia infantil. 3. ed. São Paulo: Atheneu, 1996. p. 474-84.

FONSECA, V. Manual de observação psicomotora: significação psiconeurológica dos fatores psicomotores. Porto Alegre: Artes Médicas; 1995. 8 p.

GRABOWSKI, G. A. Doenças do Depósito Lisossômico. In: BRAUNWALD, E. et al. Medicina Interna. 15. ed. Rio de Janeiro: McGraw Hill, 2002. p. 2420-2426.

GUERZONI, V. P. D. et al. Análise das intervençōes de terapia ocupacional no desempenho das atividades de vida diária em crianças com paralisia cerebral: uma revisão sistemática da literatura. Revista Brasileira de Saúde Materno Infantil, Recife, v. 8, n. 1, p. 17-25, jan./mar. 2008. http://dx.doi.org/10.1590/S1519-38292008000100003

KNOELL, K. A.; TUNNESSEN JUNIOR, W. W. Picture of the month. Hunter syndrome (mucopolysaccharidosis II A). Archives of Pediatrics \& Adolescent Medicine, Chicago, v. 154 , n. 1, p. 85-86, 2000. PMid:10632258.

LEISTNER, S.; GIUGLIANI, R. A useful routine for biochemical detection and diagnosis of mucopolysaccharidoses. Genetics and Molecular Biology, São Paulo, v. 21, n. 1, p. 163-167, Mar. 1998. http://dx.doi. org/10.1590/S1415-47571998000100028

LYNN, J. B. et al. Genética médica. 2. ed. Rio de Janeiro: Guanabara-Koogan, 2000. p. 130-132.

MAGILL, R. A. Aprendizagem Motora: conceito e aplicações. São Paulo: Edgar Blucher, 1984.

MANSUR, S. S.; MARCON, A. J. Perfil motor de crianças e adolescentes com deficiência mental moderada. Revista Brasileira de Crescimento e Desenvolvimento Humano, São Paulo, v. 16, n. 3, p. 9-15, 2006.

MARTINS, A. M. (Coord). Mucopolissacaridoses: Manual de Orientaçōes. São Paulo: UNIFESP, 2002. 23 p. Disponível em: <http://www.unifesp.br/centros/ 
creim/downloads/gz-mps-apostila-2003.pdf>. Acesso em: 10 set. 2011.

MAZER, E. P.; BARBA, P. C. S. D. Identificação de sinais de Transtornos do Desenvolvimento da Coordenação em crianças de três a seis anos e possibilidades de atuação da Terapia Ocupacional. Revista de Terapia Ocupacional da Universidade de São Paulo, São Paulo, v. 21, n. 1, p. 74-82, 2010.

MEINEL, K. Motricidade I: teoria da motricidade esportiva sob o aspecto pedagógico. Rio de Janeiro: Ao Livro Técnico S/A, 1984.

MEIRA, J. G. C.; ACOSTA, A. X. Políticas de saúde pública aplicadas à genética médica no Brasil. Revista de Ciências Médicas e Biológicas, Salvador, v. 8, n. 2, p. 189-197, 2009

MORINI, S. R. Caracterização do sistema músculoesquelético em individuos com Mucopolissacaridose tipo II: alguns aspectos cinéticos e consequências funcionais. 2007. 82 f. Tese (Mestrado em Saude da Criança e do Adolescente)-Faculdade de Ciências Médicas, Universidade Estadual de Campinas, Campinas, 2007.

NEUFELD, E. F.; MUENZER J. The mucopolysaccharidoses. In: SCRIVER, C. R. et al. (Eds.). The Metabolic and Molecular bases of Inherited disease. 8th ed. New York: McGraw Hill; 2001. p. 3421-3452.

NOORDHOEK, J.; LOSCHIAVO, F. Q. Intervenção da terapia ocupacional no tratamendo de indivíduos com doenças reumáticas utilizando a abordagem da proteção articular. Revista Brasileira de Reumatologia, São Paulo, 2005, v. 45, n. 4, p. 242-244. http://dx.doi. org/10.1590/S0482-50042005000400008.

OKUDA, P. M. M. et al. Coordenação motora fina de escolares com dislexia e transtorno do déficit de atenção e hiperatividade. Revista CEFAC, São Paulo, v. 13, n. 5, p. 876-885, set./out. 2011. http://dx.doi.org/10.1590/ S1516-18462011005000048

PERGAMENT, E. A clinical geneticist perspective of the patient-physician relationship. In: ROTHSTEIN, M. A. (Ed.). Genetic secrets: protecting privacy and confidentiality in the genetic era. New Haven; Londres: Yale University Press, 1997. p. 92-107.
PINTO, L. L. C. Um estudo sobre a história natural da mucopolissacaridose tipo II (Sindrome de Hunter) em pacientes brasileiros. 2005. 125 f. Tese (Mestrado em Genética e Biologia Molecular)-Instituto de Biociências, Universidade Federal do Rio Grande do Sul, Porto Alegre, 2005.

PINTO, L. L. C. et al. Avaliação prospectiva de 11 pacientes brasileiros com mucopolissacaridose II. Journal of Pediatrics, Saint Louis, v. 82, n. 4, p. 273-278, July/Aug. 2006. http:// dx.doi.org/10.1590/S0021-75572006000500008

RARTHMANN, M. et al. Mucopolysaccharidosis type II (Hunter syndrome): "hot spots" in the iduronate-2sulfatase gene. American Journal of Human Genetics, Chicago, v. 59, p. 1202-1209, 1996.

ROSA NETO, F. Manual de avaliação motora. Porto Alegre: Artmed, 2002.

SANJURJO-CRESPO, P. Mucopolisacaridosis de tipo II: aspectos clínicos. Revista de Neurología, Barcelona, v. 44, p. S3-S6, 2007. Suplemento 1.

SANTOS, S.; DANTAS, L.; OLIVEIRA, J. A. Desenvolvimento motor de crianças, de idosos e de pessoas com transtornos da coordenação. Revista Paulista de Educação Física, São Paulo, v. 18, p. 33-44, ago. 2004.

SCHWARTZ, I. V. D. et al. Mucopolissacaridoses. In: CARAKUSHANSKY, G. (Ed.). Doenças genéticas em pediatria. Rio de Janeiro: Guanabara Koogan, 2001. p. 180-184.

SPENCER, E. A. Disfunção musculoesquelética em adultos. In: NEISTADT, M. E.; CREPEAU, E. B. Willard \& Spackman: Terapia Ocupacional. Rio de Janeiro: Guanabara Koogan, 2002. p. 638-647.

TORRALVA, T. et al. Desarrollo mental y motor en los primeros años de vida: su relación con la estimulación ambiental y el nivel sócio-económico. Archivos Argentinos de Pediatria, Buenos Aires, v. 97, n. 5, p. 306-316, 1999.

TURTELLI, C. M. Manifestaçôes radiológicas da mucopolissacaridose tipo VI. Radiologia Brasileira, São Paulo, v. 35, n. 5, p. 311-314, out. 2002. http://dx.doi. org/10.1590/S0100-39842002000500013

VIANA, G. M. et al. Implantaçáo de um protocolo laboratorial para o diagnóstico de Mucopolissacaridoses VI e VII. Revista Brasileira de Análises Clinicas, Rio de Janeiro, v. 42, n. 2, p. 83-85, 2010.

\section{Contribuição dos Autores}

Julie Souza de Medeiros Rocha: Concepção do texto manuscrito, organização de fontes e/ou análises, redação do texto, revisão, coleta de dados. Alessandra Dounis Bonorandi: Revisão. Leilane Silva de Oliveira: Concepção do texto manuscrito, organização de fontes e/ou análises, redação do texto, coleta de dados. Maria Natália Santos da Silva: Concepçâo do texto manuscrito, organização de fontes e/ou análises, redação do texto, revisão, coleta de dados. Viviane Ferreira da Silva: Concepção do texto manuscrito, organização de fontes e/ou análises, redação do texto, coleta de dados.

\section{Notas}

${ }^{1}$ Estudo exploratório desenvolvido após aprovação da Faculdade de Terapia Ocupacional da Uncisal e da Associação de Pais e Amigos dos Excepcionais (APAE), de Maceió (AL), mediante assinatura da responsável através do Termo de Consentimento Livre e Esclarecido (TCLE). 